\title{
Lesson: Planning a garden
}

Ilyas Ahmad ${ }^{1}$

${ }^{1}$ Affiliation not available

October 8, 2020

\section{Purpose and overview:}

The main purpose of the activity is that the student will know, how their garden can benefit not just to their class room or school but also to the entire community. The student collect data to get knowledge about the impact of their activity and use this data for community engagement. The student then plan and execute a campaign to point out needs, issues, questions they got during the activity.

\section{Time:}

The activity time is a part of extended learning period that keep the student to create a school garden. This time is in the following pattern:

1. 45 minutes for class period.

2. 90 minutes for preparing the required things for the activities.

3. 45 minutes for each of the activity suggested in this section.

4. An extended service learning project for 2 to 4 weeks.

\section{Garden how to series :}

1. Global gardens(http://vimeo.com/7792707)

2. Planning your garden(http://vimeo.com/91446626)

3. Caring for your garden(http://vimeo.com/92520693)

\section{Material required for teachers:}

1. Computer with internet connection.

2. School garden or any other natural area.

3. Digital/video camera for visual recording.

4. Paper plates, utensils, napkins, serving bowls.

5. Food service for the people who attended the activity.

\section{Material required for students:}

1. A notebook for the project

2. Computer, printers, paper for creating handouts and flyers.

3. Material for presentation, demonstration and activity material.

4. Pencils or pens

5. Large sheets or white paper.

6. Map

7. Glue

8. Tap 


\section{Information technology:}

Prepare PowerPoint presentation showing characteristics of different plants.

\section{Objectives:}

This activity have the following objective

\section{knowledge :}

To describe benefits of school garden benefits of school garden for the people in community.

\section{Analysis :}

Collect data and analyze the data in school garden to evaluate its impact on community.

\section{Evaluation :}

Identify and explain some ways in which school garden engage and impact people in community.

\section{Vocabulary:}

\section{1: community engagement:}

Promoting awareness for involvement in a group activity among members of a community.

\section{2: community impact:}

Measureable effect of asocial condition, resources or activity to improve quality of life for community members.

\section{Feedback:}

Comment and evaluation about reactants to a concept, product or event that can be used as a basis for evaluations and improvement.

\section{Before the activity:}

STEM certified instructor give some basic idea for gardening to the learners.

\section{Challenge for planning a garden:}

The students along with teachers and other participants follows the following steps to create a garden for the given activity:

1. Open area selection:An open area is selected just in school or any other location.

2. Soil study: The soil of the open area is studied for the good growth of the gardens plants.

3. Sun light direction: It is the most important step for creating a garden. The direction of the sun light is studied for the good photosynthesis of the garden plants.

4. Selection of native plants: The area which is selected for the gardens should be native for the growing plants. Those plants which are not native to the given open area can't grow. 
5. Climate study: It is also an important step to create a garden, because the garden plants can best grow in that climate which is best suited for the plants growth.

6. Watering resources: As water is necessary so specific water resources should be searched and encouraged whether the availability of water is present or not.

7. Material collection:Various materials are collected to design a garden such as bricks, cement, utensils etc.

8. People visit: People are invited to check the community work of the students with teachers for the practical life and benefit themselves for creative research.

9. Publishing your garden on social media: To spread out good awareness among people that collected data and information for creating a garden is publicized on social media

\section{Information technology:}

To create your presentation on different media like power point to show the different characteristics of plants and creative community work among students, teachers and other participants 